\title{
Performance agronômica de híbridos de sorgo granífero estimada pelo método GGE biplot
}

Ludmilla Ribeiro da Rocha Gomes ${ }^{1}$, Michel Mathaus Martins Pereira ${ }^{1}$, Cícero Beserra de Menezes ${ }^{2}$, Gustavo André Simon ${ }^{1}$, Flávio Dessaune Tardin ${ }^{2}$, Milton José Cardoso ${ }^{3}$

${ }^{1}$ Universidade de Rio Verde - UniRV, Rio Verde, GO. ${ }^{2}$ Embrapa Milho e Sorgo, Sete Lagoas, MG. ${ }^{3}$ Embrapa Meio Norte, Teresina, PI. E-mail: simon@unirv.edu.br

\section{Resumo}

Uma grande vantagem do sorgo é sua característica xerófita, o que lhe atribui um potencial, como sucessão às culturas de verão, na produção de grãos, sendo fundamental a utilização de híbridos adaptados aos diferentes ambientes de cultivo. Assim, o objetivo deste trabalho foi gerar parâmetros a respeito da capacidade adaptativa de híbridos de sorgo granífero pelo método GGE biplot. Os ensaios foram conduzidos, na safrinha de 2017, em sistema de plantio direto, em quatro ambientes, Rio Verde, Sete Lagoas, Teresina e Sinop. Todos os ensaios foram conduzidos, no delineamento em blocos casualizados, com três repetições e trinta e seis híbridos. Foram avaliadas as características: florescimento, altura de plantas e produtividade de grãos. Os dados foram submetidos às análises de variância individuais e conjunta, aplicado posteriormente o critério de agrupamento de Scott-Knott e estimados os parâmetros de adaptabilidade e estabilidade. Os híbridos promissores quanto às características avaliadas e em função dos parâmetros de adaptabilidade e estabilidade foram 1610001, 1610006,1610051 e o $1 \mathrm{G} 100$.

Palavras-chave: Sorghum bicolor; adaptabilidade; estabilidade; melhoramento de plantas.

\section{Agronomic performance of granifero sorghum hybrids estimated by GGE Biplot method}

\begin{abstract}
A great advantage of sorghum it its xerophytic characteristics, which gives the potential, as a succession to summer crops in grain production. Therefore, it is fundamental to choose cultivars adapted and productive to different growing conditions. The objective of this study was to provide information about adaptive capacity of sorghum hybrids by the GGE biplot method. The trials were conducted, in 2017 as a second crop, no-tillage system, in four environments: Rio Verde, Sete Lagoas, Teresina and Sinop. All trials were conducted in a randomized complete block design with three replicates and thirty-six hybrids. The characteristics of flowering, plant height and grain yield were evaluated. It was realized individual and joint analyses of variance, after applied Scott-Knott grouping criterion and estimated the parameters of adaptability and stability. Promising hybrids for the characteristics evaluated and according to the adaptability and stability parameters were $1610001,1610006,1610051$ and $1 \mathrm{G} 100$.

Keywords: Sorghum bicolor; adaptability; stasbility; plant breeding.
\end{abstract}

\section{Introdução}

O sorgo (Sorghum bicolor, L. Moench) está entre os cinco cereais mais produzidos no mundo. A produção brasileira é de aproximadamente 2,1 milhões de toneladas, em área cultivada de aproximadamente 782,2 mil hectares, sendo Goiás o maior produtor de sorgo do Brasil, com produção de 793,3 mil toneladas
(CONAB, 2018). A importância desta cultura está relacionada com o potencial de utilização sendo empregada na produção de ração animal, forragem para animais, produção de vassoura, etanol, alimentação humana, produção de farinha para panificação e amido industrial (QUEIROZ et al., 2014). 
As grandes vantagens desta cultura são suas características xerófitas, que lhe atribui um potencial como sucessão a culturas de verão, na produção de grãos, especialmente a soja. Pois neste período ocorre a segunda safra, em que a frequência das chuvas é menos frequente. Sendo assim, é fundamental a escolha de cultivares adaptadas, produtivas e com valor agregado a diferentes condições de cultivo (FREITAS et al., 2009).

Os programas de melhoramento genético de sorgo desenvolvem um número significativo de linhagens homozigotas e, a partir dos cruzamentos entre elas, são gerados vários híbridos experimentais. $O$ estudo sobre 0 desempenho dos híbridos em vários locais e a dinâmica da interação genótipos por ambientes é de extrema importância, de forma a selecionar aqueles mais adaptados e estáveis, principalmente às condições de estresse hídrico, viabilizando o cultivo em regiões com limitações na ocorrência de precipitação, como nas regiões de clima semiárido ou no centro-oeste e sudeste, em períodos de segunda safra (MENEZES et al., 2015).

Apesar de ser relevante no melhoramento genético, os componentes da interação genótipos por ambientes, informações pormenorizadas sobre o comportamento de cada genótipo influenciado pelas variações ambientais é possível empregando análises de adaptabilidade e estabilidade. $O$ parâmetro de adaptabilidade refere-se à magnitude da responsividade dos genótipos em função do estímulo do ambiente e o parâmetro de estabilidade permite identificar aqueles que apresentam comportamento previsível (CRUZ et al., 2014).

Para auxiliar a seleção de híbridos estáveis e com ampla adaptação foram desenvolvidas várias metodologias para a estimação de parâmetros de adaptabilidade e estabilidade, entre eles o modelo GGE biplot (Genotype main effects + Genotype environment interaction), que considera o efeito principal de genótipo mais a interação genótipos e ambientes (YAN et al., 2000).

Diante do exposto, o objetivo deste trabalho foi gerar informações a respeito da capacidade adaptativa de híbridos de sorgo granífero nas diferentes condições de ambiente de cultivo.

\section{Material e Métodos}

Os ensaios foram conduzidos na safrinha de 2017, em sistema de plantio direto, em quatro estados. Na área experimental da Universidade de Rio Verde, no município de Rio Verde - GO ( $871 \mathrm{~m}$ de altitude, $17^{\circ} 47^{\prime} 14^{\prime \prime}$ S e $50^{\circ} 57^{\prime} 38^{\prime \prime}$ O), com solo classificado como Latossolo Vermelho distroférrico, o clima para a localidade é do tipo $A w$, que recebe o nome de clima tropical com estação seca, caracterizado por apresentar chuvas mais intensas no verão em comparação ao inverno.

$\mathrm{Na}$ estação experimental da EMBRAPA Milho e Sorgo, localizada em Sete Lagoas - MG (767 m de altitude, 19 27' 57' S e 44ㅇ 14' 49" O), com solo classificado como Latossolo Vermelho distrófico e clima dominante do tipo Cwa, mesotérmico úmido, apresenta verão quente e chuvoso (outubro a março) e inverno seco (abril a setembro), sendo a precipitação média anual de $1.367 \mathrm{~mm}$. Na estação experimental da EMBRAPA Meio Norte em Teresina - PI $(61,0 \mathrm{~m}$ de altitude, $05^{\circ} 02^{\prime} 8,6^{\prime \prime} \mathrm{S}$ e $42^{\circ} 47^{\prime} 7,4^{\prime \prime} \mathrm{O}$ ), solo classificado como Argissolo Vermelho-Amarelo distrófico, clima do tipo Aw e caracterizado como subúmido seco, megatérmico, com excedente hídrico moderado no verão. $\mathrm{Na}$ estação experimental da EMBRAPA Agrossilvipastoril em Sinop - MT ( $384 \mathrm{~m}$ de altitude, $11^{\circ} 52^{\prime} 27^{\prime \prime}$ S e $55^{\circ} 30^{\prime} 22^{\prime \prime}$ O), solo classificado como Latossolo VermelhoAmarelo distrófico, clima do tipo Aw, tropical. A classificação do solo estabelecida segundo EMBRAPA (2013) e o clima conforme classificação de Köppen e dados climáticos apresentados na Figura 1.

Foi empregado em todos os experimentos, o delineamento experimental em blocos casualizados, e três repetições. As parcelas experimentais foram constituídas por quatro fileiras de 5 metros de comprimento, espaçadas por 0,50 metros entre si, e a área útil foi composta pelas duas fileiras centrais, desprezando 0,5 metros das extremidades.

Os experimentos foram constituídos por trinta e seis híbridos de sorgo granífero, entre eles trinta e um experimentais, desenvolvidos pela Embrapa Milho e Sorgo (1516045, 1610009, $1516053,1619044,1610023,1610033,1610039$, $1528039,1527025,1610043,1516047,1610049$, $1610055,1610037,1516035,1610041,1610029$, $1610011,1516033,1421020,1527019,1420038$, $1610006,1610001,1610027,1516051,1528025$, 1420020, 1610051, 1621043 e 1516049) e cinco 
híbridos comerciais utilizados como testemunha (BRS373, BRS330, 1G220, 1G100 e Fox).

O plantio manual dos experimentos ocorreu em março de 2017, sendo no dia dois em Rio Verde, nove em Sete Lagoas, seis em Sinop e quatorze em Teresina. O manejo fitossanitário, em todos os locais foi realizado conforme exigências da cultura e necessidade observada, em levantamentos amostrais (EMBRAPA, 1982). A população final foi de aproximadamente 180 mil plantas por hectare, após a realização do desbaste. A colheita dos experimentos foi realizada em julho de 2017, sendo em Rio Verde e Sinop no dia doze, Sete Lagoas no dia vinte e oito e Teresina no dia vinte e cinco.

Figura 1. Precipitação pluvial e temperatura média do ar em Rio Verde (a), Sinop (b), Sete Lagoas (c) e Teresina (d) durante a safrinha de 2017. Fonte: Estações automáticas INMET.
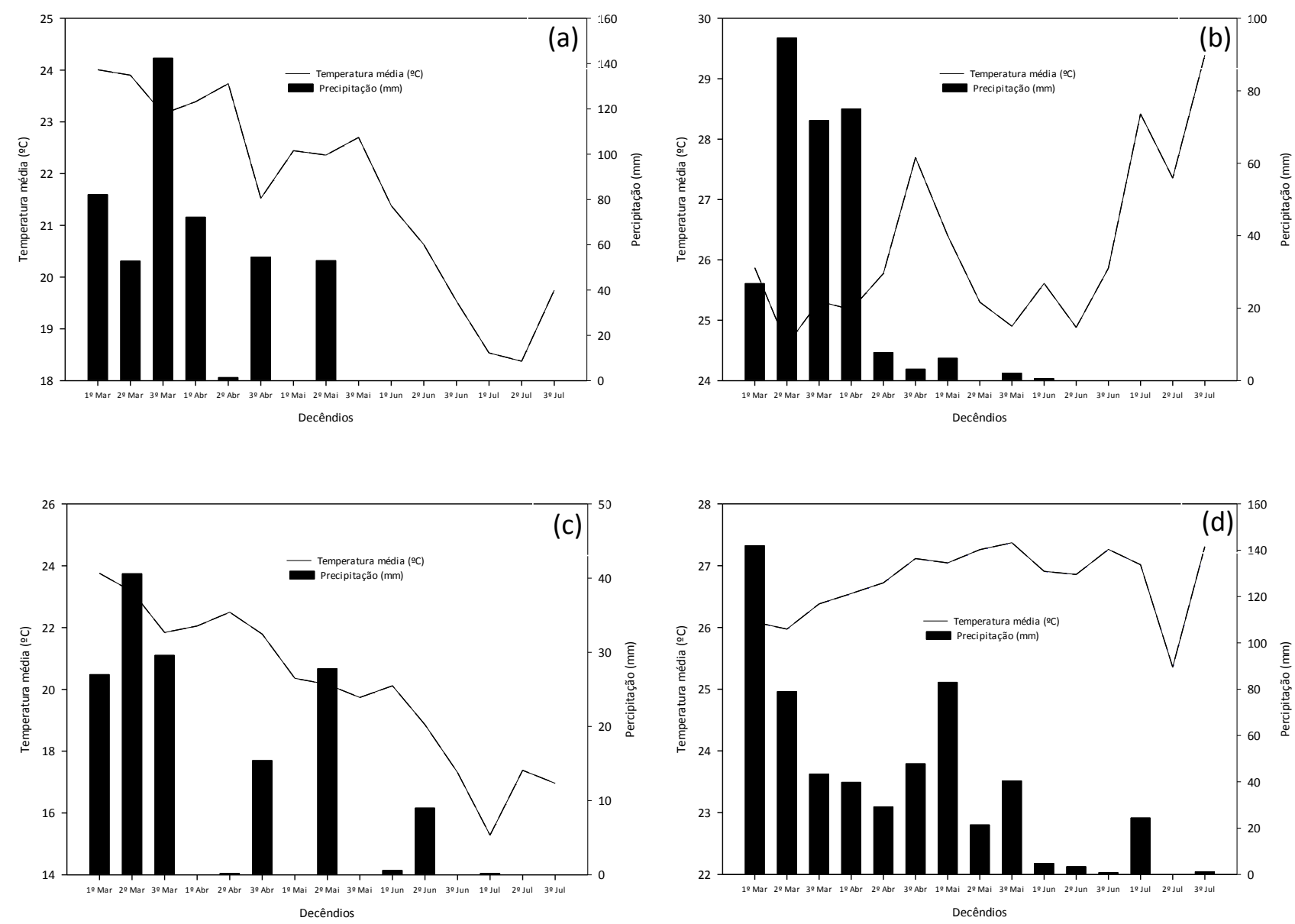

As características avaliadas foram: a) Florescimento, considerando-se o número de dias da semeadura até o florescimento, o qual foi definido quando, na parcela, em mais de $50 \%$ das plantas, as flores do terço médio da panícula entraram em antese; b) Altura de planta, medindo-se em centímetros da superfície do solo ao ápice da panícula, considerando amostra de dez plantas por parcela; c) Produtividade de grãos, obtida a partir da colheita das panículas da área útil da parcela e posterior trilhagem e pesagem dos grãos, sendo os valores extrapolados para t ha ${ }^{-1}$ e corrigidos para $13 \%$ de umidade.

Os dados de todas as características avaliadas foram submetidos à análise de variância individual, por ambiente, sendo constatada a homogeneidade das variâncias residuais, permitindo assim, a realização da análise de variância conjunta dos ensaios.

Para a realização das análises de variância, foi considerado como fixo o efeito de híbridos e as demais fontes de variação como aleatórias. A análise de variância individual foi realizada segundo o modelo: $Y_{i j}=\mu+G_{i}+B_{j}+\varepsilon_{i j}$, sendo, $Y_{i j}$ : valor da determinada característica observada na parcela que recebeu o genótipo $\mathrm{i}$, alocado no bloco $j$; $\mu$ : constante geral; $G_{i}$ : efeito fixo do $i-$ 
ésimo genótipo; $B_{\mathrm{j}}$ : efeito aleatório do j-ésimo bloco; $\varepsilon_{\mathrm{ij}}$ : efeito aleatório do erro experimental observado na parcela ij; $\varepsilon_{\mathrm{ij}} \sim \operatorname{NID}\left(0, \sigma^{2}\right)$.

O modelo estatístico adotado para análise de variância conjunta, considerando todos os experimentos, foi: $Y_{i j k}=\mu+B_{k}\left(A_{j}\right)+G_{i}+A_{j}+G_{i} A_{j}+$ $\varepsilon_{\mathrm{ijk}}$; sendo, $B_{k}\left(A_{j}\right)$ : o efeito aleatório do bloco $k$ no ambiente $\mathrm{j} ; A_{\mathrm{j}}$ : o efeito aleatório do j-ésimo ambiente; $\mathrm{G}_{\mathrm{i}} \mathrm{A}_{\mathrm{j}}$ : efeito aleatório da interação entre o genótipo i com o ambiente j e $\varepsilon_{\mathrm{ijk}}$ : o efeito aleatório do erro experimental observado na parcela ${ }_{\mathrm{ijk}} ; \varepsilon_{\mathrm{ij}} \sim \operatorname{NID}\left(0, \sigma^{2}\right)$. Para o agrupamento de médias dos genótipos, foi utilizado o critério de agrupamento de Scott-Knott, sendo todas as análises realizadas utilizando o programa Genes (CRUZ, 2013). Posteriormente, os dados de produtividade de grãos foram submetidos à análise de adaptabilidade e estabilidade usando a metodologia GGE biplot (YAN, 2000).

$O$ modelo biplot GGE utilizado foi: $Y_{\mathrm{ij}}-\mu-\beta_{\mathrm{j}}$ $=\mathrm{y}_{1} \varepsilon \mathrm{i}_{1} \rho \mathrm{j}_{1}+\mathrm{y}_{2} \varepsilon \mathrm{i} \rho \mathrm{j}_{2}+\varepsilon_{\mathrm{ij}}$, sendo $\mathrm{Y}_{\mathrm{ij}}$ : o rendimento médio de grãos do genótipo i no ambiente j; $\mu$ : a média geral de observações; $\beta_{j}$ : o principal efeito do meio ambiente; $y_{1}$ e $y_{2}$ são os erros associados ao primeiro ( $\mathrm{PC1}$ ) e ao segundo componente principal ( $P C 2$ ), respectivamente; $\varepsilon_{1}$ e $\varepsilon_{2}$ : os valores de $\mathrm{PC1}$ e $\mathrm{PC2}$, respectivamente, para o genótipo da ordem $\mathrm{i} ; \rho_{\mathrm{j} 1}$ e $\rho_{\mathrm{j} 2}$ : são os valores de PC1 e PC2, respectivamente, para o ambiente de ordem j; $\varepsilon_{\mathrm{ij}}$ : é o erro associado ao modelo de o ith genótipo e j-th ambiente (YAN et al., 2000).

\section{Resultados e Discussão}

Observa-se que houve diferença significativa entre ambientes e híbridos e ocorreu interação híbridos $x$ ambientes significativa para todas as características avaliadas (Tabela 1). A significância entre ambientes $\mathrm{x}$ híbridos demonstra que há variabilidade genética e fenotípica, entre os híbridos testados, as quais influenciaram no comportamento diferencial dos híbridos em função dos ambientes testados. Resultados semelhantes foram obtidos por Silva et al. (2009), que também observaram efeito significativo, para híbridos, ambientes e interação para todas essas características.

O coeficiente de variação foi satisfatório para a maioria das características avaliadas, observando valores baixos, conforme a classificação de Pimentel Gomes (2009), que demonstra haver alta precisão experimental nos resultados obtidos.

O florescimento em Rio Verde variou de 62 dias (1610051) até 74 dias (1528025), em Sinop de 52 dias $(1421020,1516035$ e 1516045) até 64 dias (1G220), em Sete Lagoas de 62 dias (FOX) até 76 dias (1610029) e em Teresina de 52 dias (1516045 e 1516053) até 64 dias (1G220) (Tabela 2).

Os híbridos 1516035 e 1516053 foram os que tiveram o período de florescimento inferior aos demais, na maioria dos ambientes, não diferindo das testemunhas comerciais $1 \mathrm{G} 100$ e FOX e apresentando ciclo mais precoce. Já o híbrido 1420020 e a testemunha BRS373 apresentaram maior média de florescimento em todos os ambientes, característica que geralmente está correlacionada com maiores produtividades de grãos em período de cultivo favorável para a cultura (ZANATTO et al., 2016).

Os híbridos podem se comportar de maneira diferente em vários ambientes, podendo diferenciar o ciclo em função das diferentes épocas de semeadura. Por isso, a importância de existir genótipos, com diferentes períodos de florescimento disponíveis para o agricultor, minimizando riscos à cultura e favorecendo o escalonamento da colheita (ALMEIDA FILHO et al., 2014). 
Tabela 1. Resumo da análise de variância conjunta para florescimento (FL), altura de plantas (AP) e produtividade de grãos (PROD), avaliadas em quatro ambientes: Rio Verde-GO, Sete Lagoas-MG, Sinop-MT e Teresina-PI, na segunda safra de 2017 com 36 combinações híbridas.

\begin{tabular}{lcccc}
\hline \multirow{2}{*}{$\mathrm{FV}$} & $\mathrm{GL}$ & \multicolumn{3}{c}{ Quadrados Médios } \\
\cline { 3 - 5 } & & $\mathrm{FL}$ (dias) & $\mathrm{AP}(\mathrm{cm})$ & $\mathrm{PROD}\left(\mathrm{t} \mathrm{ha}^{-1}\right)$ \\
\hline Bloco (ambiente) & 8 & 4,10 & 90,83 & 2,98 \\
Ambiente & 3 & $4677,71^{*}$ & $71595,29 * *$ & $60,88^{* *}$ \\
Híbrido & 35 & $56,82^{* *}$ & $1386,95^{* *}$ & $11,94^{* *}$ \\
Ambiente x Híbrido & 105 & $23,06^{* *}$ & $144,23 * *$ & $1,44^{*}$ \\
\hline Híbrido (RV) & 35 & $22,92^{*}$ & $378,07^{* *}$ & $4,51^{* *}$ \\
Híbrido (Sinop) & 35 & $31,90^{* *}$ & $614,69^{* *}$ & $3,42^{* *}$ \\
Híbrido (SL) & 35 & $39,30^{* *}$ & $637,54^{* *}$ & $5,38^{* *}$ \\
Híbrido (Teresina) & 35 & $31,90^{* *}$ & $189,34^{*}$ & $2,96^{* *}$ \\
Erro & 280 & 4,17 & 66,00 & 0,96 \\
\hline CV (\%) & - & 3,22 & 6,84 & 23,25 \\
Média & - & 63,53 & 118,75 & 4,23 \\
\hline
\end{tabular}

**, * Significativo a $1 \%$ e $5 \%$ de probabilidade, respectivamente, pelo teste $\mathrm{F}$.

A precocidade é uma característica interessante para cultivares de sorgo granífero, pois como o cultivo é realizado principalmente na safrinha, podendo coincidir com condições adversas do clima. A semeadura do sorgo na safrinha aumenta o risco de redução na produtividade de grãos, em decorrência da possibilidade de ocorrência de estresse hídrico (TARDIN et al., 2013; MENEZES et al., 2015).

A altura da planta de sorgo granífero está correlacionada positivamente com a produtividade de grãos, no entanto, o porte consideravelmente alto aumenta a probabilidade de acamamento, sendo preferível plantas de porte médio. Observa-se que houve diferença significativa, para altura de plantas, em todos os ambientes (Tabela 1). Em Rio Verde, apesar de todos os híbridos apresentarem a altura com menor discrepância, quatro híbridos (1610051, 1610055,1619044 e 1621043 ) obtiveram menor porte em relação aos demais e não diferiram significativamente entre si. Já em Sinop, três híbridos (1610049, 1610055 e 1619044) e a testemunha BRS373 se destacaram e diferiram dos demais apresentando menor porte (Tabela $3)$.

Em Sete Lagoas, nove híbridos e uma testemunha diferiram significativamente dos demais, apresentando menor altura, com médias variando de $89 \mathrm{~cm}$ (1619044) a $107 \mathrm{~cm}$ (1621043). Em Teresina, apenas o hibrido 1420020 foi superior a $1,00 \mathrm{~m}$, sendo os demais inferiores a este valor (Tabela 3). Em trabalhos de avaliação de cultivares de sorgo granífero, Silva et al. (2009) observaram intervalos de altura entre $0,71 \mathrm{~m}$ a $1,14 \mathrm{~m}$ e Almeida Filho et al. (2014) os intervalos entre $0,96 \mathrm{~m}$ a $1,55 \mathrm{~m}$.

O híbrido com aspectos favoráveis em relação a altura de plantas não pode ser baixo a ponto de limitarem a produtividade de grãos e nem muito alto tornando-o suscetível ao acamamento (MENEZES et al., 2015). Os híbridos que obtiveram porte favorável em mais de um ambiente foram 1610011, 1610027, 1610043, 1610049, 1610051, 1621043 e a testemunha BRS373 (Tabela 3). 
Tabela 2. Média da característica florescimento em dias, dos trinta e seis híbridos avaliados nos quatro ambientes, Rio Verde-GO, Sete Lagoas-MG, Sinop-MT e Teresina-PI, na segunda safra de $2017^{1}$.

\begin{tabular}{|c|c|c|c|c|c|}
\hline Híbridos & Rio Verde & Sinop & Sete Lagoas & Teresina & Médias \\
\hline 1420020 & $71 \mathrm{c}$ & $59 \mathrm{c}$ & $72 \mathrm{c}$ & $58 \mathrm{c}$ & 65 \\
\hline 1420038 & $68 \mathrm{~b}$ & $60 \mathrm{c}$ & $75 \mathrm{~d}$ & $55 \mathrm{~b}$ & 64 \\
\hline 1421020 & $71 \mathrm{c}$ & 52 a & $69 \mathrm{~b}$ & $57 \mathrm{~b}$ & 62 \\
\hline 1516033 & $72 \mathrm{c}$ & 55 a & $74 d$ & $56 \mathrm{~b}$ & 64 \\
\hline 1516035 & $66 a$ & 52 a & $70 \mathrm{~b}$ & $54 a$ & 60 \\
\hline 1516045 & $66 \mathrm{~b}$ & 52 a & $67 \mathrm{~b}$ & 52 a & 59 \\
\hline 1516047 & $70 \mathrm{c}$ & $54 a$ & $72 \mathrm{c}$ & $56 \mathrm{~b}$ & 63 \\
\hline 1516049 & $67 b$ & $59 \mathrm{c}$ & $74 \mathrm{~d}$ & $57 b$ & 64 \\
\hline 1516051 & $71 \mathrm{c}$ & $56 \mathrm{~b}$ & $72 \mathrm{c}$ & $57 \mathrm{~b}$ & 64 \\
\hline 1516053 & 63 a & $53 a$ & $67 \mathrm{~b}$ & 52 a & 59 \\
\hline 1527019 & 66 a & $56 \mathrm{~b}$ & $70 \mathrm{c}$ & $54 a$ & 61 \\
\hline 1527025 & 65 a & $61 \mathrm{~d}$ & $69 \mathrm{~b}$ & $62 d$ & 64 \\
\hline 1528025 & $74 \mathrm{c}$ & $59 \mathrm{c}$ & $72 \mathrm{c}$ & $59 \mathrm{c}$ & 66 \\
\hline 1528039 & $72 \mathrm{c}$ & 55 a & $70 \mathrm{c}$ & $55 \mathrm{~b}$ & 63 \\
\hline 1610001 & $66 \mathrm{~b}$ & $60 \mathrm{c}$ & $70 \mathrm{c}$ & $59 \mathrm{c}$ & 64 \\
\hline 1610006 & $67 \mathrm{~b}$ & $60 \mathrm{c}$ & $74 \mathrm{~d}$ & $59 \mathrm{c}$ & 65 \\
\hline 1610009 & $64 a$ & $57 \mathrm{~b}$ & $65 a$ & $55 \mathrm{~b}$ & 60 \\
\hline 1610011 & $68 \mathrm{~b}$ & $59 \mathrm{c}$ & $71 \mathrm{c}$ & $57 \mathrm{~b}$ & 64 \\
\hline 1610023 & $66 \mathrm{~b}$ & $59 \mathrm{c}$ & $75 \mathrm{~d}$ & $56 \mathrm{~b}$ & 64 \\
\hline 1610027 & $67 \mathrm{~b}$ & $59 \mathrm{c}$ & $72 \mathrm{c}$ & $61 \mathrm{~d}$ & 64 \\
\hline 1610029 & $72 \mathrm{c}$ & $59 \mathrm{c}$ & $76 \mathrm{~d}$ & $61 \mathrm{~d}$ & 67 \\
\hline 1610033 & 65 a & $57 \mathrm{~b}$ & $69 \mathrm{~b}$ & $55 \mathrm{~b}$ & 61 \\
\hline 1610037 & $68 \mathrm{~b}$ & $60 \mathrm{c}$ & $68 \mathrm{~b}$ & $61 \mathrm{~d}$ & 64 \\
\hline 1610039 & $70 \mathrm{c}$ & $62 \mathrm{~d}$ & $68 \mathrm{~b}$ & $62 \mathrm{~d}$ & 65 \\
\hline 1610041 & $67 \mathrm{~b}$ & $59 \mathrm{c}$ & $66 \mathrm{~b}$ & $60 \mathrm{c}$ & 63 \\
\hline 1610043 & $64 a$ & $57 \mathrm{~b}$ & $70 \mathrm{c}$ & $55 \mathrm{~b}$ & 62 \\
\hline 1610049 & $67 \mathrm{~b}$ & $61 \mathrm{~d}$ & $68 \mathrm{~b}$ & $62 d$ & 65 \\
\hline 1610051 & $62 a$ & $57 \mathrm{~b}$ & $67 \mathrm{~b}$ & $55 \mathrm{~b}$ & 60 \\
\hline 1610055 & $69 \mathrm{c}$ & $63 \mathrm{~d}$ & $67 \mathrm{~b}$ & $62 d$ & 65 \\
\hline 1619044 & $70 \mathrm{c}$ & $54 a$ & $74 \mathrm{~d}$ & $53 a$ & 63 \\
\hline 1621043 & $70 \mathrm{c}$ & $63 d$ & $66 \mathrm{~b}$ & $63 d$ & 65 \\
\hline $1 \mathrm{G} 100$ & 65 a & $54 a$ & $63 a$ & $56 \mathrm{~b}$ & 59 \\
\hline $1 G 220$ & $71 \mathrm{c}$ & $64 \mathrm{~d}$ & $63 a$ & $64 \mathrm{~d}$ & 65 \\
\hline BRS330 & $68 \mathrm{~b}$ & $58 \mathrm{c}$ & $75 \mathrm{~d}$ & $58 \mathrm{c}$ & 65 \\
\hline BRS373 & $67 b$ & $56 \mathrm{~b}$ & $69 \mathrm{~b}$ & $55 \mathrm{~b}$ & 62 \\
\hline FOX & $68 \mathrm{~b}$ & 53 a & $62 a$ & $54 a$ & 59 \\
\hline Médias & $68 \mathrm{~B}$ & $57 \mathrm{~A}$ & $70 \mathrm{C}$ & $57 \mathrm{~A}$ & \\
\hline
\end{tabular}

${ }^{1}$ Médias seguidas pela mesma letra minúscula na coluna e maiúscula na linha, agrupam-se pelo critério de Scott-knott, a $5 \%$ de probabilidade.

Pode-se observar diferença significativa na produtividade de grãos em todos os ambientes (Tabela 1). A média geral da produtividade de grãos em Rio Verde foi de $4,74 \mathrm{t} \mathrm{ha}^{-1}$ e apresentando variação de $1,51 \mathrm{t} \mathrm{ha}^{-1}$ (1528039) a $6,78 \mathrm{t} \mathrm{ha}^{-1}$ (1610011). Em Sinop, as médias 
variaram de $0,45 \mathrm{t} \mathrm{ha}^{-1}$ (1528039) até $4,70 \mathrm{t} \mathrm{ha}^{-1}$ (1610029), com média de $3,18 \mathrm{t} \mathrm{ha}^{-1}$. A variação ocorrida em Sete Lagoas foi de 1,13 $\mathrm{t} \mathrm{ha}^{-1}$ (15280397) a 7,73 $\mathrm{t} \mathrm{ha}^{-1}$ (1610006), sendo a média de 4,81 $\mathrm{t} \mathrm{ha}^{-1}$. Já em Teresina, ocorreu variação de $1,89 \mathrm{t} \mathrm{ha}^{-1}$ (1528039) a 6,28 $\mathrm{t} \mathrm{ha}^{-1}$ (1610039), com média geral de 4,19 $\mathrm{t} \mathrm{ha}^{-1}$ (Tabela 4). Destacam-se Rio Verde e Sete Lagoas com produtividade média de grãos significativamente superiores à Sinop e Teresina.

No município de Rio Verde, vinte e um híbridos apresentaram médias da produtividade de grãos significativamente superiores aos demais, entre eles estão duas das testemunhas. Em Sinop foram vinte híbridos que se destacaram sendo uma testemunha; e em Sete Lagoas somente dez híbridos apresentaram médias superiores aos demais sendo uma testemunha; e em Teresina, vinte e três híbridos superaram significativamente os demais. Os híbridos que se destacaram em pelo menos três ambientes foram $1420020,1516035,1516045,1516049,1516053$, $1527019,1527025,1610009,1610011,1610023$, 1610037, 1610039, 1610041, 1610049, 1610055, 1621043 e a testemunha $1 \mathrm{G100}$. E os híbridos que se destacaram nos quatro ambientes foram 1610001, 1610006 e 1610051 (Tabela 4), sugerindo que os mesmos apresentam maior capacidade de adaptação nos ambientes de cultivo desta cultura. 
Tabela 3. Média da característica altura de plantas em centímetros dos trinta e seis híbridos avaliados nos quatro ambientes: Rio Verde-GO, Sete Lagoas-MG, Sinop-MT e Teresina-PI, na segunda safra de $2017^{1}$.

\begin{tabular}{|c|c|c|c|c|c|c|c|c|c|}
\hline Híbridos & Rio Ver & rde & Sino & & Sete La & goas & Teresi & & Médias \\
\hline 1420020 & 135 & c & 180 & e & 140 & $d$ & 108 & c & 141 \\
\hline 1420038 & 123 & $b$ & 147 & c & 127 & c & 83 & a & 120 \\
\hline 1421020 & 139 & $d$ & 146 & c & 128 & c & 99 & c & 128 \\
\hline 1516033 & 142 & $d$ & 149 & c & 135 & $d$ & 83 & a & 127 \\
\hline 1516035 & 148 & $d$ & 154 & c & 152 & $d$ & 84 & a & 134 \\
\hline 1516045 & 149 & $d$ & 157 & $d$ & 135 & $d$ & 81 & a & 130 \\
\hline 1516047 & 133 & c & 154 & c & 131 & c & 91 & $b$ & 127 \\
\hline 1516049 & 140 & $d$ & 136 & $b$ & 114 & $b$ & 86 & $b$ & 119 \\
\hline 1516051 & 135 & c & 158 & $d$ & 122 & c & 86 & $b$ & 125 \\
\hline 1516053 & 141 & $d$ & 159 & $d$ & 130 & c & 83 & $a$ & 128 \\
\hline 1527019 & 124 & $b$ & 145 & c & 110 & $b$ & 76 & $a$ & 114 \\
\hline 1527025 & 117 & b & 131 & $b$ & 109 & $b$ & 81 & $a$ & 109 \\
\hline 1528025 & 140 & $d$ & 154 & c & 127 & c & 88 & $b$ & 127 \\
\hline 1528039 & 150 & d & 153 & c & 141 & $d$ & 92 & $b$ & 134 \\
\hline 1610001 & 130 & c & 136 & $b$ & 111 & $b$ & 79 & $a$ & 114 \\
\hline 1610006 & 141 & $d$ & 143 & c & 123 & c & 85 & $b$ & 123 \\
\hline 1610009 & 132 & c & 164 & $d$ & 131 & c & 83 & $a$ & 127 \\
\hline 1610011 & 122 & b & 128 & $b$ & 100 & a & 79 & $a$ & 107 \\
\hline 1610023 & 127 & b & 158 & $d$ & 122 & c & 80 & $a$ & 122 \\
\hline 1610027 & 130 & c & 142 & c & 102 & $a$ & 78 & $a$ & 113 \\
\hline 1610029 & 137 & c & 158 & $d$ & 137 & $d$ & 89 & $b$ & 130 \\
\hline 1610033 & 135 & c & 152 & c & 127 & c & 85 & $b$ & 125 \\
\hline 1610037 & 131 & c & 148 & c & 112 & $b$ & 81 & $a$ & 118 \\
\hline 1610039 & 121 & $b$ & 137 & $b$ & 103 & $a$ & 89 & $b$ & 112 \\
\hline 1610041 & 131 & c & 150 & c & 118 & $b$ & 94 & $b$ & 123 \\
\hline 1610043 & 119 & $b$ & 136 & $b$ & 99 & $a$ & 69 & $a$ & 105 \\
\hline 1610049 & 118 & b & 123 & $a$ & 99 & $a$ & 80 & $a$ & 105 \\
\hline 1610051 & 114 & $a$ & 129 & $b$ & 102 & a & 76 & $a$ & 105 \\
\hline 1610055 & 106 & $a$ & 122 & $a$ & 106 & $a$ & 79 & $a$ & 103 \\
\hline 1619044 & 107 & $a$ & 111 & a & 89 & a & 67 & $a$ & 93 \\
\hline 1621043 & 114 & $a$ & 132 & $b$ & 107 & $a$ & 74 & $a$ & 106 \\
\hline $1 \mathrm{G} 100$ & 122 & $b$ & 128 & $b$ & 118 & $b$ & 82 & $a$ & 112 \\
\hline $1 G 220$ & 125 & $b$ & 129 & $b$ & 110 & $b$ & 83 & $a$ & 112 \\
\hline BRS330 & 127 & $b$ & 147 & c & 117 & b & 86 & $b$ & 119 \\
\hline BRS373 & 119 & $b$ & 122 & $a$ & 103 & $a$ & 70 & $a$ & 103 \\
\hline FOX & 124 & $\mathrm{~b}$ & 141 & $\mathrm{C}$ & 129 & C & 79 & $\mathrm{a}$ & 118 \\
\hline Médias & 129 & C & 143 & D & 118 & B & 83 & A & \\
\hline
\end{tabular}

${ }^{1}$ Médias seguidas pela mesma letra minúscula na coluna e maiúscula na linha, agrupam-se pelo critério de Scott-knott, a $5 \%$ de probabilidade.

A maior parte dos híbridos apresentou média de produtividade (Tabela 4) acima da média nacional do ano agrícola de 2017 que foi de $2,85 \mathrm{t} \mathrm{ha}^{-1}$ (CONAB, 2018). Vale ressaltar, que de todas as testemunhas que fizeram parte do experimento somente a FOX, em Sinop, ficou abaixo da média nacional. A média geral de cada 
ambiente foi próxima a do trabalho realizado por Silva et al. (2013), que foi de 5,15 $\mathrm{t} \mathrm{ha}^{-1}$.

Em geral, apenas três híbridos experimentais e uma testemunha se destacaram em produtividade de grãos e florescimento em apenas dois ambientes. Sendo estes o 1516035 em Rio Verde e Sinop, 1516053 e 1527019 em Rio Verde e Teresina e a testemunha 16100 em Rio Verde e Sete Lagoas. Os híbridos experimentais que destacaram em relação à produtividade de grãos e altura de plantas em dois ambientes foram o 1610049 em Sinop e Teresina e o 1621043 em Rio Verde e Teresina. No entanto, apenas quatro híbridos experimentais e uma testemunha se destacaram, em relação ao florescimento, altura de plantas e produtividade de grãos, sugerindo assim, melhor capacidade de adaptação em determinado ambiente, sendo eles o 1610051 em Rio Verde e o 1516045, 1516053, 1527019 e FOX em Teresina. Vale ressaltar, que dois híbridos experimentais apresentaram aspectos favoráveis em todas as características avaliadas, sendo eles o 1610051 em Rio Verde,
Sete Lagoas e Teresina e o 1610055 em Rio Verde, Sinop e Teresina (Tabelas 2, 3 e 4).

Ao analisar o resultado da análise de variância conjunta constatou-se a interação significativa entre ambientes e híbridos para a característica produtividade de grãos, o que justifica o uso da análise de adaptabilidade e estabilidade, para a identificação de genótipos estáveis e adaptados aos ambientes de interesse.

Esta análise foi realizada pelo método GGE biplot que agrupa o efeito aditivo do genótipo com o efeito multiplicativo da interação GxA e submetendo-a à análise de componentes principais, facilitando na construção do gráfico para identificar os padrões de desempenho dos genótipos, além de facilitar a visualização da média, estabilidade dos mesmos e a relação entre ambientes. Além disso, é possível identificar os ambientes que mais contribuem, para a composição da interação GxA (YAN, 2011). 
Tabela 4. Média da característica produtividade de grãos em $\mathrm{t} \mathrm{ha}^{-1}$ dos trinta e seis híbridos avaliados nos quatro ambientes: Rio Verde-GO, Sete Lagoas-MG, Sinop-MT e Teresina-PI, na segunda safra de $2017^{1}$.

\begin{tabular}{|c|c|c|c|c|c|c|c|c|}
\hline Códigos & Híbridos & Rio Ver & & Sinop & & Sete Lagoas & Teresina & Médias \\
\hline 1 & 1610001 & 6,57 & $a$ & 4,41 a & a & 5,88 a & $5,48 \quad a$ & 5,59 \\
\hline 2 & 1610011 & 6,78 & a & 4,09 & $a$ & $4,96 \mathrm{~b}$ & $4,84 a$ & 5,17 \\
\hline 3 & 1610027 & 4,42 & $b$ & 4,05 a & a & $4,40 \mathrm{~b}$ & 4,59 a & 4,36 \\
\hline 4 & 1610039 & 5,39 & $a$ & 4,69 a & a & $4,52 \quad b$ & 6,28 a & 5,22 \\
\hline 5 & BRS373 & 4,22 & $b$ & $2,83 k$ & $b$ & $3,70 \mathrm{c}$ & 4,35 a & 3,77 \\
\hline 6 & 1610049 & 4,82 & a & $2,82 k$ & $b$ & $3,78 \mathrm{c}$ & 4,73 a & 4,74 \\
\hline 7 & 1610051 & 4,83 & a & 3,84 a & a & $6,54 a$ & $4,39 a$ & 4,90 \\
\hline 8 & 1610055 & 6,22 & $a$ & 3,51 a & a & $5,09 \mathrm{~b}$ & $4,42 a$ & 4,81 \\
\hline 9 & 1610006 & 5,44 & a & 4,05 a & $\mathrm{a}$ & $7,73 a$ & 5,42 a & 5,66 \\
\hline 10 & 1516049 & 6,43 & a & 3,73 & $\mathrm{a}$ & $4,71 \mathrm{~b}$ & $5,33 a$ & 5,05 \\
\hline 11 & 1610023 & 5,80 & a & $2,75 k$ & b & $5,77 a$ & $4,76 a$ & 4,77 \\
\hline 12 & 1610037 & 5,39 & a & 4,45 a & a & $4,83 \mathrm{~b}$ & 4,08 a & 4,68 \\
\hline 13 & 1610043 & 4,82 & a & $2,82 k$ & $b$ & $3,78 \mathrm{c}$ & $4,73 a$ & 4,04 \\
\hline 14 & 1527025 & 5,24 & a & 4,19 & $\mathrm{a}$ & $5,45 b$ & 4,53 a & 4,85 \\
\hline 15 & 1527019 & 5,48 & a & 3,77 a & $\mathrm{a}$ & $5,50 \mathrm{~b}$ & $4,77 \quad a$ & 4,88 \\
\hline 16 & 1621043 & 5,22 & a & 3,39 & $a$ & $5,05 \mathrm{~b}$ & $4,04 a$ & 4,43 \\
\hline 17 & 1610009 & 3,81 & $b$ & 3,47 a & $\mathrm{a}$ & 5,61 a & $5,37 a$ & 4,56 \\
\hline 18 & 1610033 & 3,63 & $b$ & 3,64 & $\mathrm{a}$ & $4,63 \mathrm{~b}$ & $3,14 b$ & 3,76 \\
\hline 19 & 1610041 & 5,81 & a & 3,77 a & a & $5,43 \mathrm{~b}$ & 4,95 a & 4,99 \\
\hline 20 & 1619044 & 2,84 & c & $0,91 c$ & c & $1,43 \mathrm{~d}$ & $2,75 b$ & 1,99 \\
\hline 21 & 1516033 & 3,74 & $b$ & 1,78 & c & $3,73 \mathrm{c}$ & $3,11 \mathrm{~b}$ & 3,09 \\
\hline 22 & 1516047 & 4,15 & $b$ & 1,73 & c & $3,17 \mathrm{c}$ & $3,29 b$ & 3,09 \\
\hline 23 & 1516051 & 3,11 & b & 2,14 & b & $3,66 \mathrm{c}$ & $2,91 \mathrm{~b}$ & 2,96 \\
\hline 24 & 1421020 & 5,34 & a & 2,23 & $b$ & $3,70 \mathrm{c}$ & $2,77 \quad b$ & 3,51 \\
\hline 25 & 1516035 & 5,37 & a & 3,23 & $a$ & $6,13 a$ & $3,87 \mathrm{~b}$ & 4,65 \\
\hline 26 & 1516045 & 4,67 & a & $2,60 k$ & b & 5,79 a & $4,94 a$ & 4,50 \\
\hline 27 & 1516053 & 5,30 & a & $2,62 k$ & $b$ & $5,70 a$ & $4,74 a$ & 4,59 \\
\hline 28 & 1528039 & 1,51 & c & 0,45 & c & $1,13 \mathrm{~d}$ & $1,89 \mathrm{~b}$ & 1,24 \\
\hline 29 & 1528025 & 1,90 & c & 1,22 & c & $3,87 \mathrm{c}$ & $2,36 \mathrm{~b}$ & 2,34 \\
\hline 30 & 1420038 & 3,63 & b & 3,73 & $\mathrm{a}$ & $4,99 \mathrm{~b}$ & $3,85 \mathrm{~b}$ & 4,05 \\
\hline 31 & 1610029 & 4,20 & b & 4,70 & $\mathrm{a}$ & 4,86 b & $3,06 \mathrm{~b}$ & 4,20 \\
\hline 32 & 1420020 & 4,32 & $b$ & 4,49 & $\mathrm{a}$ & $6,66 a$ & 4,46 a & 4,98 \\
\hline 33 & BRS330 & 3,80 & $b$ & 3,15 a & $a$ & 4,48 b & $3,77 \mathrm{~b}$ & 3,80 \\
\hline 34 & $1 \mathrm{G} 100$ & 5,95 & a & $2,99 k$ & b & $6,84 a$ & 5,15 a & 5,24 \\
\hline 35 & Fox & 4,16 & $b$ & $2,26 k$ & $b$ & $3,88 \mathrm{c}$ & $4,25 a$ & 3,64 \\
\hline \multirow[t]{2}{*}{36} & $1 G 220$ & 5,08 & a & 2,90 & b & $5,00 \mathrm{~b}$ & $3,36 \mathrm{~b}$ & 4,09 \\
\hline & Médias & 4,74 & A & 3,18 & C & $4,81 \mathrm{~A}$ & $4,19 \mathrm{~B}$ & \\
\hline
\end{tabular}

${ }^{1}$ Médias seguidas pela mesma letra minúscula na coluna e maiúscula na linha, agrupam-se pelo critério de Scott-knott, a 5\% de probabilidade.

O método GGE biplot, foi formado por dois componentes principais, PC1 e PC2, que são derivados da decomposição dos valores singulares dos efeitos de genótipos (G) e da interação GxA. O primeiro componente principal
PC1 indica que a adaptabilidade dos genótipos é altamente correlacionada com a produtividade, enquanto o segundo componente principal PC2 indica a estabilidade fenotípica, ou seja, os 
genótipos com PC2 mais próximos de zero são mais estáveis (BATISTA et al., 2017).

Os valores do PC1 e PC2 correspondem a $74,43 \%$ e $12,36 \%$ da variação total dos dados, respectivamente (Figura 2). No entanto, estes valores dão consistência à explicação da variação total da produtividade de grãos dos híbridos, além da interação com os ambientes ( $G+G \times A)$. $A$ relação entre produtividade de grãos $e$ estabilidade é analisada do ponto de vista vetorial dos ambientes, em que estes são conectados por vetores com a origem biplot (YAN, 2011). Ainda segundo o autor, os vetores pequenos dentro do ambiente indicam que a estabilidade do rendimento é alta. Então, ambientes com vetores menores são mais estáveis, assim, Teresina e Sinop foram os ambientes que menos contribuíram para interação GxA, apresentando a menor diferença de produtividade entre os híbridos avaliados. Rio Verde e Sete Lagoas foram os ambientes que apresentaram o maior vetor, sendo os que mais contribuíram para a interação GxA (Figura 2).

Figura 2. Relação entre os ambientes obtidos pelo modelo GGE biplot para produtividade de grãos de trinta e seis híbridos de sorgo cultivados em Rio Verde-GO (RV), Teresina-PI (TES), Sinop-MT (SIN) e Sete Lagoas$M G(S L)$.

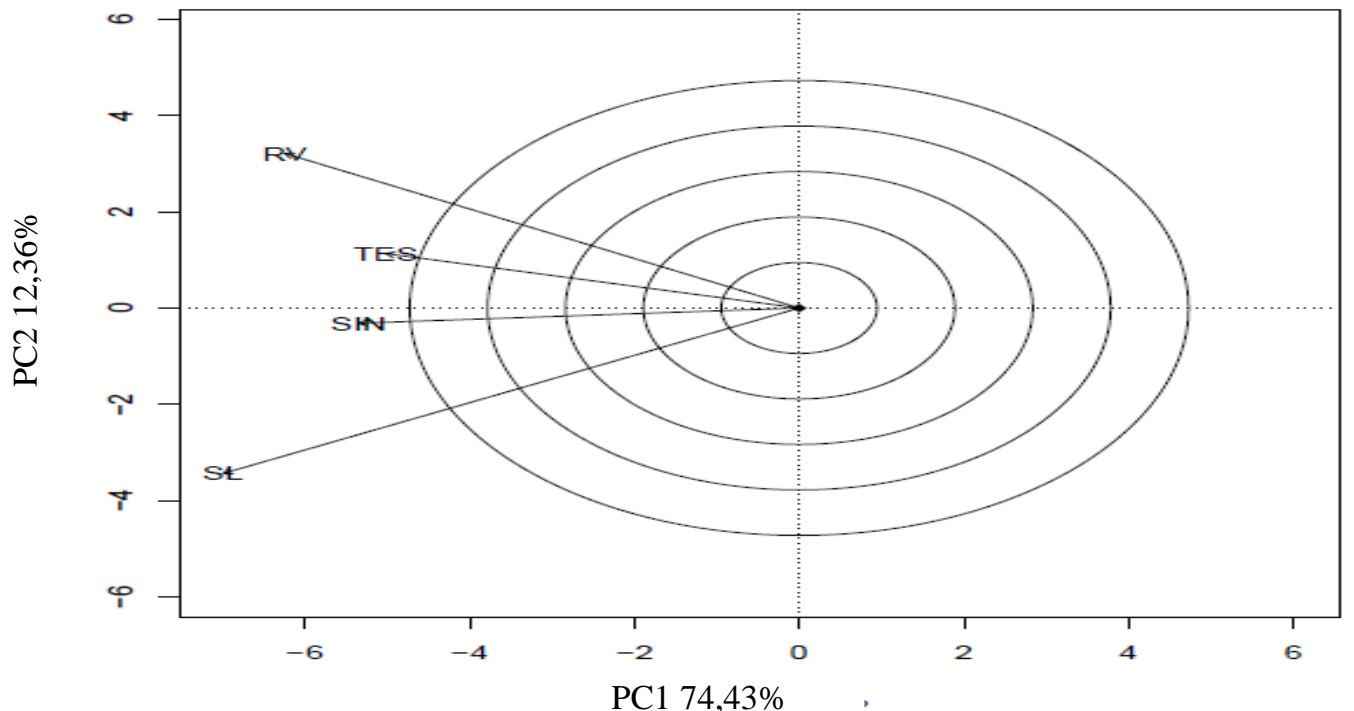

A presença de ângulos largos e obtusos entre os ambientes de teste é indicativo de interação GxA, ou seja, quanto menor o ângulo entre os ambientes, mais estabilidade eles promovem (HONGYU et al., 2015). Com isso os ambientes Teresina e Sinop de acordo com a figura 1 são os mais estáveis. 0 polígono está formado pela conexão dos vértices que estão mais afastados da origem do biplot, sendo conectados pelos híbridos 28 (1528039), 20 (1619044), 10 (1516049), 2 (1610011), 1 (1610001), 9 (1610006), 32 (1420020) e 29 (1528025). Tais híbridos possuem os maiores vetores, em suas respectivas direções, sendo o comprimento e o sentido do vetor que simbolizam a medida de respostas dos genótipos aos ambientes testados. Ou seja, o tamanho dos vetores e suas respectivas direções estão diretamente relacionados com a adaptabilidade de cada genótipo aos ambientes, dentro do mesmo setor. Todos os outros híbridos estão contidos no polígono e apresentam vetores menores, ou seja, são menos responsivos em relação à interação, com os ambientes dentro daquele setor (Figura 3). 
Figura 3. Polígono do GGE biplot representando o gráfico quem venceu onde, para os trinta e seis híbridos em Rio Verde-GO (RV), Teresina-PI (TES), Sinop-MT (SIN) e Sete Lagoas-MG (SL). Os códigos dos híbridos estão presentes na Tabela 4.

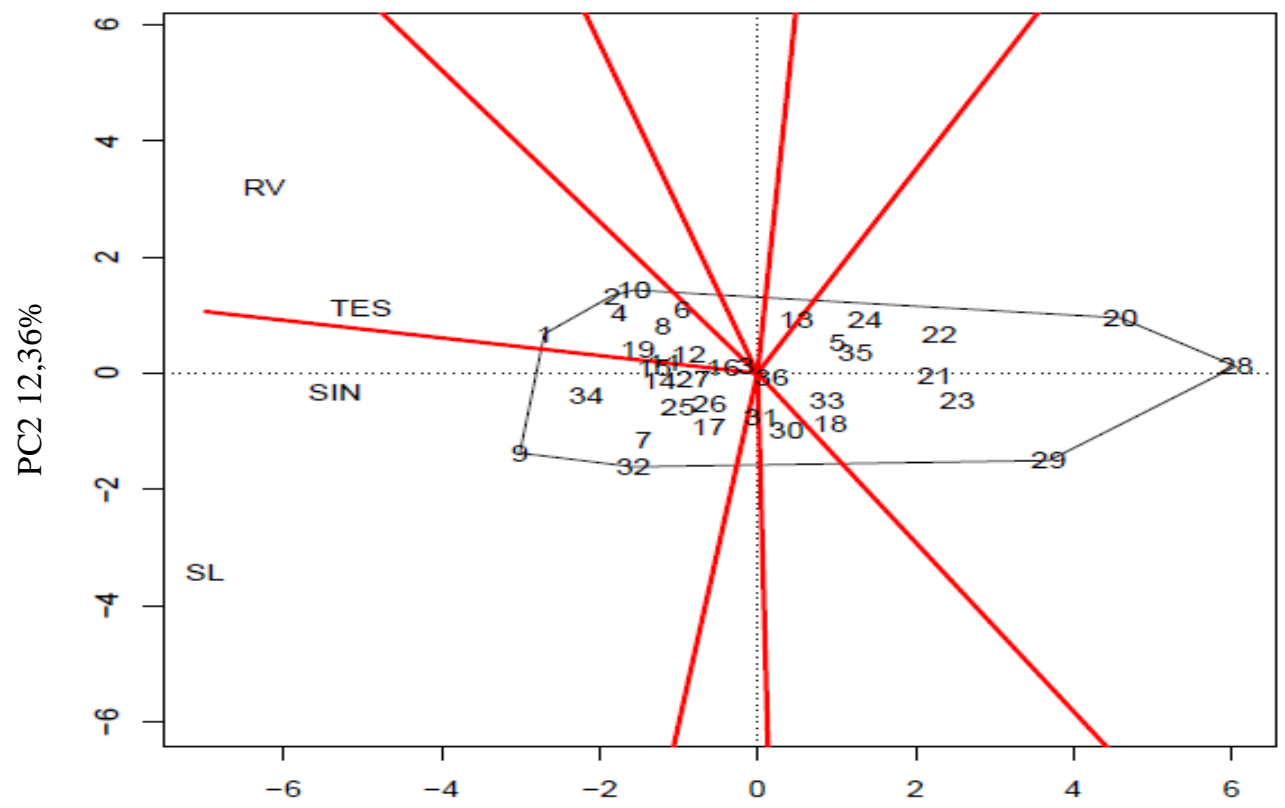

PC1 $74,43 \%$

Os vetores do centro biplot $(0,0)$, que são perpendiculares aos lados do polígono, dividiram o gráfico em oito setores (Figura 3). Resultados semelhantes foram observados por Batista et al. (2017), que obtiveram gráficos divididos em oito setores ao avaliarem o rendimento de grãos de vinte e nove híbridos de sorgo cultivados sob condições de estresse hídrico e de não-estresse em Nova Porteirinha-MG, em 2014 e 2015, e em Teresina-PI, em 2014.

Em relação ao desempenho dos híbridos nos ambientes de experimentação, uma característica interessante é o híbrido encontrase no vértice do polígono, dentro de um megaambiente, significa que obteve a maior produtividade e adaptabilidade, em pelo menos um dos ambientes e esteve dentre os melhores híbridos nos ambientes restantes. Assim, o híbrido 1 (1610001) foi o mais adaptado aos ambientes Rio Verde e Teresina por ser o vértice desses ambientes, e os híbridos 10 (1516049), 2 (1610011), 4 (1610039), 6 (1610049), 8 (1610055), 19 (1610041), 12 (1610037),16 (1621043) e 3 (1610027) que estão contidos dentro do polígono entre Teresina e Rio Verde também apresentaram boa adaptabilidade a esses ambientes. Já o híbrido 9 (1610006) é o vértice dos ambientes Sinop e Sete Lagoas, sendo este o mais adaptado a esses ambientes, os demais híbridos 32 (1420020), 15 (1527019), 14
(1527025), 27 (1516053), 34 (1G100), 25 (1516035), 26 (1516045), 7 (1610051) e 17 (1610009) também demonstraram boa adaptabilidade aos ambientes, em que estão contidos (Figura 3). Portanto, todos esses híbridos além de apresentarem maior adaptabilidade foram os mais produtivos.

Apesar do híbrido 28 (1528039) se localizar no vértice do polígono e ser muito estável juntamente com os híbridos 20 (1619044) e 29 (1528025), eles apresentaram os menores valores de produtividade de grãos, nos quatro ambientes. Portanto, os híbridos que compõem um setor que não contempla ambientes, são considerados não adaptados aos ambientes testados, especialmente, por baixa produtividade (KARIMIZADEH et al., 2013).

Outra forma de visualizar a adaptabilidade e estabilidade é através da figura 4 , em que observa-se um pequeno círculo do lado esquerdo, no qual representa o 'ambiente-média' sendo definido pelas coordenadas médias de todos os ambientes de teste no biplot, com a seta apontando para um maior desempenho médio para os híbridos. Quanto maior a distância de projeção do híbrido em relação à linha reta, menor é a sua estabilidade (YAN, 2011).

Sendo assim os híbridos que apresentaram a melhor média de produtividade, acima da média geral na maioria dos ambientes foram: 32 
(1420020), 9 (1610006), 7 (1610051), 10 (1516049), 2 (1610011), 4 (1610039), 6 (1610049), 8 (1610055), 1 (1610001), 17 (1610009), 25 (1516035), 26 (1516045), 19 (1610041), 12 (1610037), 34 (1G100), 14 (1527025), 27 (1516053), 15 (1527019), 16 (1621043) e 3 (1610027). Além da alta produtividade todos estes híbridos foram estáveis, exceto o 2 (1610011), 10 (1516049), 9 (1610006), 7 (1610051) e o 32 (1420020) que foram mais instáveis dentre os híbridos de melhor produtividade (Figura 4).

Os híbridos de menor produtividade em todos os ambientes foram 29 (1528025), 20 (1619044) e 28 (1528039), demonstrando que as suas médias em todos os ambientes ficaram abaixo da média geral de cada ambiente. Os agrupamentos das médias tanto para maior ou menor produtividade são observados na tabela 4.

Figura 4. Médias $x$ estabilidade do GGE biplot, indicando o ranking de produtividade dos híbridos e suas respectivas estabilidades produtivas em Rio Verde-GO (RV), Teresina-PI (TES), Sinop-MT (SIN) e Sete Lagoas-MG (SL). Os códigos dos híbridos estão presentes na Tabela 4.

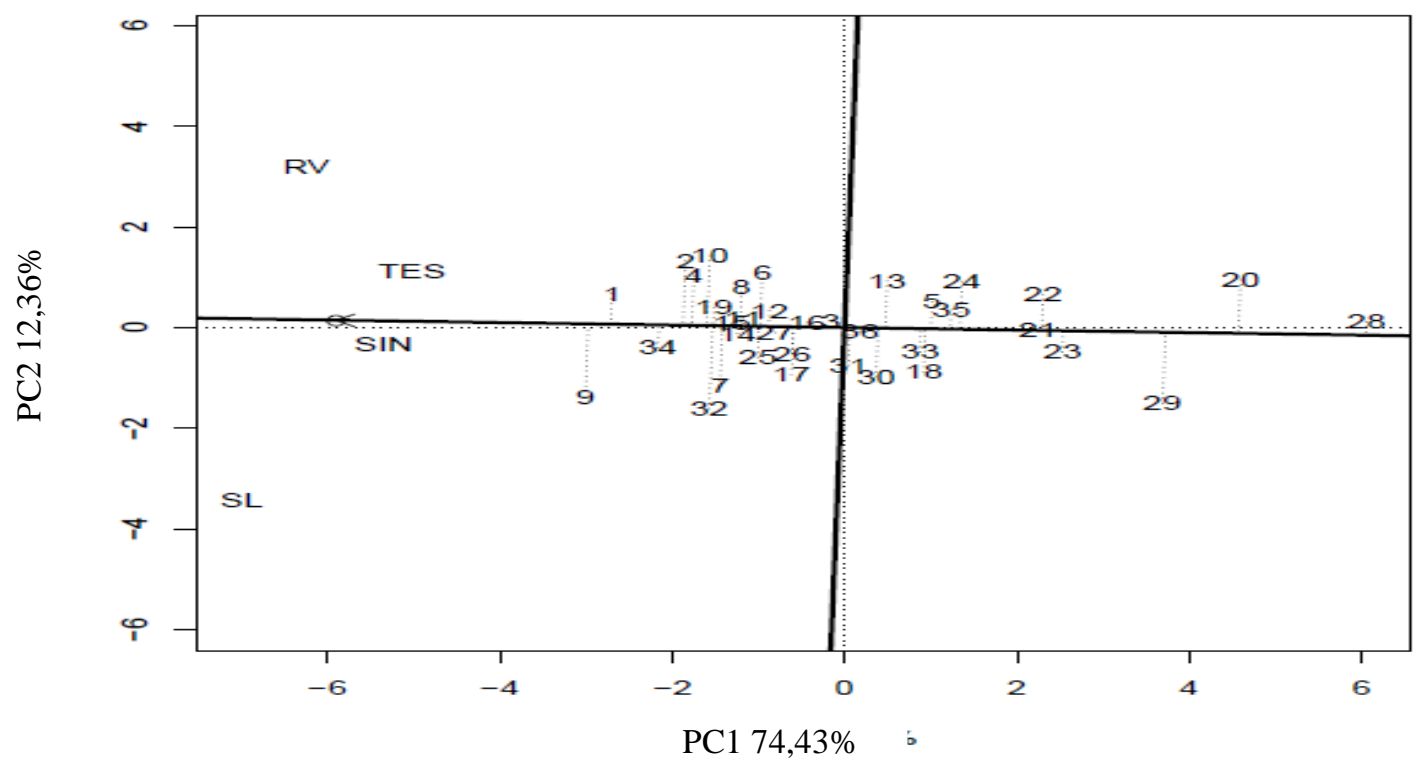

Um híbrido é mais promissor se ele estiver localizado o mais próximo possível do genótipo ideal. Quanto mais próximo do centro dos círculos concêntricos, mais útil é o híbrido, significando que apresenta parâmetros favoráveis de adaptabilidade, ou seja, é responsivo aos ambientes testados e estabilidade de produtividade, a qual significa maior previsibilidade de comportamento (YAN, 2011).

O híbrido ideal é o 1 (1610001) que está contido no primeiro círculo, em seguida o 34
(1G100) e os híbridos 2 (1610011), 10 (1516049), 4 (1610039), 8 (1610055), 19 (1610041), 15(1527019), 14 (1527025), 25 (1516035), 7 (1610051) e 9 (1610006) estão contidos no segundo círculo concêntrico e são os que mais se aproximaram do híbrido ideal, sendo considerados deste modo, híbridos desejáveis, em termos de produtividade e estabilidade (Figura 5). 
Figura 5. Modelo do GGE biplot comparando os híbridos avaliados com a estimativa de um híbrido ideal. Os códigos dos híbridos estão presentes na Tabela 4.

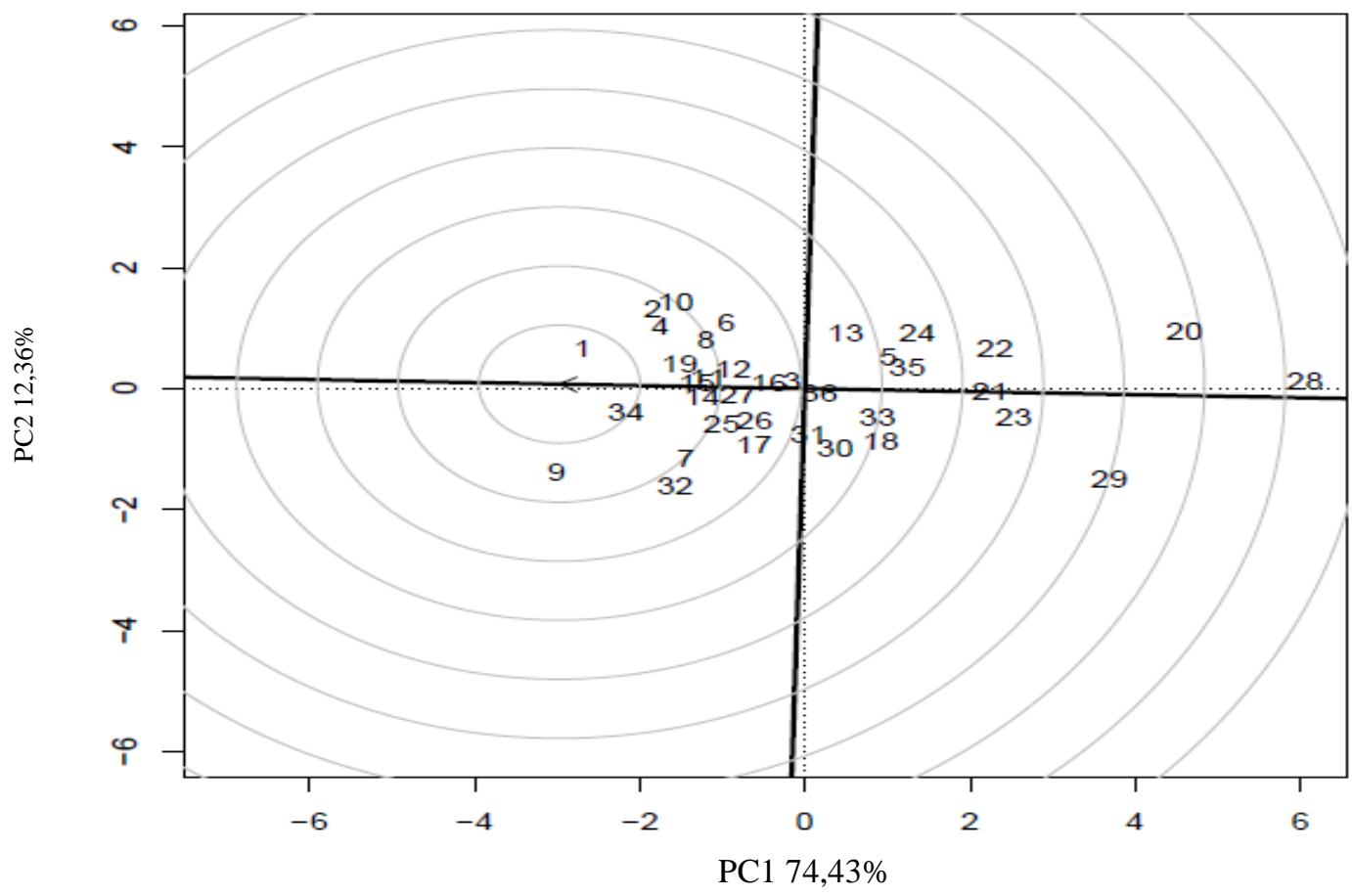

Analisando as médias das características avaliadas e os parâmetros de adaptabilidade e estabilidade, destacam-se doze com aspectos favoráveis sendo eles: 1610001, 1610011, $1610039,1610051,1610055,1610006,1516049$, $1527025,1527019,1610009,1610041$ e $1 \mathrm{G} 100$, que apresentaram melhor produtividade, adaptabilidade e estabilidade.

Em geral, todos os híbridos apresentaram baixa variação em relação ao ciclo e ao porte da planta, entretanto, os híbridos experimentais 1610001, 1610006 e 1610051, além do híbrido comercial 1G100, sobressaíram por associar aspectos favoráveis em relação às características avaliadas e estimativas favoráveis dos parâmetros de adaptabilidade e estabilidade. Desta forma, entende-se que estes híbridos apresentaram maior responsividade nos ambientes avaliados, bem como destacam-se pela previsibilidade de comportamento.

\section{Conclusões}

Os híbridos 1610001, 1610006, 1610051 e $1 \mathrm{G} 100$ associaram altas produtividades de grãos e aspectos favoráveis em relação a altura de planta e florescimento com estimativas favoráveis de adaptabilidade e estabilidade.

\section{Referências}

ALMEIDA FILHO, J.E.; TARDIN, F.D.; DAHER, R.F.; SILVA, K.J.; XAVIER NETO, J.B.; BASTOS, E.; LOPES,
V.S.; BARBÉ, T.C.; MENEZES, C.B. Avaliação agronômica de híbridos de sorgo granífero em diferentes regiões produtoras do Brasil. Revista Brasileira de Milho e Sorgo, v.13, n.1, p. 82-95, $2014 . \quad$ https://doi.org/10.18512/19806477/rbms.v13n1p82-95

BATISTA, P.S.C.; MENEZES, C.B.; CARVALHO, A.J.; PORTUGAL, A.F.; BASTOS, E.A.; CARDOSO, M.J.; SANTOS, C.V.; JULIO, M.P.M. Performance of grain sorghum hybrids under drought stress using GGE biplot analyses. Genetics and Molecular Research, v.16, n.3, p.1-12, 2017. http://dx.doi.org/10.4238/gmr16039761

CONAB. Acompanhamento de safra brasileira Grãos, Safra 2017/18. Nono Levantamento, v. 5. Brasília: Conab, 2018. 146p.

CRUZ, C.D. GENES - a software package for analysis in experimental statistics and quantitative genetics. Acta Scientiarum, v.35, n.3, p.271-276, 2013.

http://dx.doi.org/10.4025/actasciagron.v35i3.212 $\underline{51}$

CRUZ, C. D.; CARNEIRO, P. C. S.; REGAZZI, A. J. Modelos biométricos aplicados ao melhoramento genético. 3. ed. Viçosa: UFV, 2014. 668p. 
EMBRAPA. Recomendações técnicas para a cultura do sorgo granífero. Sete Lagoas: EMBRAPA Milho e Sorgo, 1982. 39p. (Circular Técnica, 5).

EMBRAPA. Sistema Brasileiro de Classificação de Solos. 3. ed. Rio de Janeiro: Embrapa Solos, 2013. $353 \mathrm{p}$.

FREITAS, R.S.; BORGES, W.L.B.; SILVA, G.S. Realidade e perspectiva para cultura do sorgo granífero no Estado de São Paulo. In: ENCONTRO SOBRE TECNOLOGIAS DE PRODUÇÃO DE MILHO E SORGO. Anais [...]. Campinas: IAC, 2009. p.1-11. (Documentos IAC, 89).

HONGYU, K.; SILVA, F. L.; OLIVEIRA, A.C.S.; SARTI, D.A.; ARAUJO, L.B.; DIAS, C.T.S. Comparação entre os modelos ammi e gge biplot para os dados de ensaios multi-ambientais. Revista Brasileira de Biometria, v.33, n.2, p.139-155, 2015.

KARIMIZADEH, R.; MOHAMMADI, M.; SABAGHNI, N.; MAHMOODI, A. A. GGE biplot analysis of yield stability in multienvironment trials of lentil genotypes under rainfed condition. Notulae Scientia Biologicae, v.5, n.2, p.256-262, 2013. http://dx.doi.org/10.15835/nsb.5.2.9067

MENEZES, C.D.; RIBEIRO, A.S.; TARDIN, F.D.; CARVALHO, A.J.; BASTOS, E.A.; CARDOSO, M.J.; PORTUGAL, A.F.; SILVA, K.J.; SANTOS, C.V.; ALMEIDA, F.H.L. Adaptabilidade e estabilidade de linhagens de sorgo em ambientes com e sem restrição hídrica. Revista Brasileira de Milho e Sorgo, v.14, n.1, p.101-115, 2015.

MENEZES, C. B.; SILVA, A. F.; TARDIN, F. D. Sorgo safrinha. In: PEREIRA FILHO, I. A.; RODRIGUES, J. A.S. (Ed.). Sorgo: o produtor pergunta, a Embrapa responde. Brasília: Embrapa, 2015. cap. 18, p. 293-308. (Coleção 500 perguntas, 500 respostas). https://doi.org/10.18512/1980-

6477/rbms.v14n1p101-115

PIMENTEL GOMES, F. Curso de estatística experimental. 15. ed. Piracicaba: ESALQ, 2009. 451p.

QUEIROZ, V.A.; MORAES, E.A.; MARTINO, H.S. D.; PAIVA, C.L.; MENEZES, C.B. Potencial do sorgo para uso na Alimentação Humana. Informe Agropecuário, v.35, n.278, p.7-12, 2014.
SILVA, A.G.; BARROS, A.S.; SILVA, L.H.C.P.; MORÃES, E.B.; PIRES, R.; TEIXEIRA, I.R. Avaliação de cultivares de sorgo granífero na safrinha no sudoeste do Estado de Goiás. Pesquisa Agropecuária Tropical, v.39, n.2, p.168-174, 2009.

SILVA, K.J.; MENEZES, C.B.; TARDIN, F.D.; MARTIEMYGDIO, B.; SOUZA, V.F.; CARVALHO, G.A.; SILVA, M.J. Seleção de híbridos de sorgo granífero cultivados no verão em três localidades. Revista Brasileira de Milho e Sorgo, v.12, n.1, p.44-53, 2013. https://doi.org/10.18512/19806477/rbms.v12n1p44-53

TARDIN, F.D.; ALMEIDA FILHO, J.E..; OLIVEIRA, C.M.; LEITE, C.D.P.; MENEZES, C.B.; MAGALHÃES, P.C.; RODRIGUES, J.A.S.; SCHAFFERT, R.E. Avaliação agronômica de híbridos de sorgo granífero cultivados sob irrigação e estresse hídrico. Revista Brasileira de Milho e Sorgo, v.12, n.2, p.102-117, 2013. https://doi.org/10.18512/1980-

6477/rbms.v12n2p102-117

ZANATTO, I. B. et al. Identificação de caracteres relacionados à precocidade e produtividade em híbridos de sorgo via correlações canônicas. Revista Científica Intelletto, v. 1, n. 1, p. 89-94, 2016.

YAN, W. GGE Biplot vs. AMMI Graphs for Genotype-by-Environment Data Analysis. Journal of the Indian Society of Agricultural Statistics, v.65, n.2, p.181-193, 2011.

YAN, W.; HUNT, L.A.; SHENG, Q.; SZLAVNICS, Z. Cultivar evaluation and mega-environment investigation based on the GGE Biplot. Crop Science, v.40, n.3, p.597-605, 2000. https://doi.org/10.2135/cropsci2000.403597x 